\title{
Antibiotic management of acute pharyngitis in primary care
}

\author{
The Advisory Group on Antibiotic Stewardship Programme in Primary Care
}

This article was published on 31 Jan 2019 at www.hkmj.org.

\section{A B S T R A C T}

The Centre for Health Protection of the Department of Health has convened the Advisory Group on Antibiotic Stewardship Programme in Primary Care (the Advisory Group) to formulate guidance notes and strategies for optimising judicious use of antibiotics and enhancing the Antibiotic Stewardship Programme in Primary Care. Acute pharyngitis is one of the most common conditions among outpatients in primary care in Hong Kong. Practical recommendations on the diagnosis and antibiotic treatment of acute streptococcal pharyngitis are made by the Advisory Group based on the best available clinical evidence, local prevalence of pathogens and associated antibiotic susceptibility profiles, and common local practice.

\section{Hong Kong Med J 2019;25:58-63}

https://doi.org/10.12809/hkmj187544

The Advisory Group on Antibiotic Stewardship Programme in Primary Care

(Group members are listed at the end of the paper)

Corresponding author: edmanlam@cuhk.edu.hk

\section{Introduction}

The Government of the Hong Kong Special Administrative Region attaches great importance to the threat of antimicrobial resistance. Under the authority of the Food and Health Bureau, and with collaborative efforts from stakeholders, the Hong Kong Strategy and Action Plan on Antimicrobial Resistance (2017-2022) was established in July 2017. Recommendations in six key areas and 19 objectives were included in this Action Plan, aiming to slow the emergence of antimicrobial resistance and prevent its spread.

In connection with this Action Plan, the Centre for Health Protection of the Department of Health convened the Advisory Group on Antibiotic Stewardship Programme in Primary Care (the Advisory Group) comprising key stakeholders in the public and private sectors, academia, and major professional societies. Its objective is to formulate guidance notes and strategies for optimising the judicious use of antibiotics and enhancing the Antibiotic Stewardship Programme in Primary Care (https://www.chp.gov.hk/en/features/49811. html). Guidance notes on antibiotic treatments for common infections seen by primary care doctors have been developed based on the best available clinical evidence, local prevalence of pathogens and associated antibiotic susceptibility profiles, and local practice. Clinical evidence has mainly referred to international practices, the latest guidelines from international organisations, and systematic review articles. In addition, simple information sheets for out-patients are prepared to raise awareness and enable them to use antibiotics appropriately. Primary care doctors play an important role in antimicrobial resistance containment measures by not only practising rational antibiotic prescriptions but also educating and engaging out-patients about the safe use of antibiotics during clinical encounters.

Acute pharyngitis is the acute inflammation of the oropharynx. It is characterised by sore throat and pharyngeal erythema. It is one of the most common conditions among out-patients in primary care in Hong Kong. ${ }^{1,2}$

Acute pharyngitis is usually a benign, selflimiting illness with an average length of illness of 1 week. It is often caused by respiratory viruses (eg, rhinovirus, coronavirus, adenovirus, influenza virus, parainfluenza virus, respiratory syncytial virus and metapneumovirus). The other viruses of concern are enterovirus, herpes simplex virus, Epstein-Barr virus, cytomegalovirus, and human immunodeficiency virus (HIV). Viral pharyngitis is a condition for which antibiotics are not necessary. Out-patients with a sore throat and associated symptoms and signs, including conjunctivitis, coryza, cough, discrete ulcerative stomatitis, hoarseness, diarrhoea, and viral exanthema, are most likely to have a viral illness, such as common cold, influenza, herpangina, and oral herpes.

Beta-haemolytic streptococci, particularly group A Streptococcus (GAS), are the most common bacterial pathogens of acute pharyngitis. Group A Streptococcus is estimated to be responsible for approximately $10 \%$ of cases of acute pharyngitis in adults and $15 \%$ to $30 \%$ of those in children. ${ }^{3}$ A local study at an accident and emergency department in Hong Kong showed that for those presenting with a sore throat and without symptoms of common cold or influenza, the prevalence rates of GAS pharyngitis 
were $2.65 \%$ in adults and adolescents aged $>14$ years and $38.6 \%$ in children aged 3 to 14 years; none of the children aged $<3$ years had GAS pharyngitis. ${ }^{4}$ Group A Streptococcus pharyngitis can lead to suppurative (eg, quinsy, otitis media, and other invasive infections) and non-suppurative (eg, acute rheumatic fever, poststreptococcal glomerulonephritis) complications. However, acute rheumatic fever has not been described as a complication of either group C Streptococcus or group G Streptococcus pharyngitis. Streptococcal pharyngitis is the most common form of acute pharyngitis, in which antibiotic treatment is indicated.

\section{Diagnosis of acute streptococcal pharyngitis}

There are different recommendations on the diagnostic strategy of acute streptococcal pharyngitis. Ideally, to obtain a definitive diagnosis, out-patients with symptoms and signs suggestive of a bacterial cause (eg, sudden onset of fever, anterior cervical lymphadenopathy, tonsillopharyngeal exudates) should be tested for GAS with a rapid antigen detection test (RADT) and/or throat culture..$^{5-8} \mathrm{~A}$ negative RADT should be backed up by a throat culture in children and adolescents, but not in adults. Practically and clinically, different various clinical scoring criteria have been developed to estimate the likelihood of acute streptococcal pharyngitis, and we recommend that practitioners make clinical decisions about laboratory testing and/or antibiotic prescribing. ${ }^{9-11}$ The FeverPAIN score was developed in the primary care setting in the United Kingdom in 2013. ${ }^{12}$ The Centor criteria were developed in the emergency department setting in the United States in 1981; the modified Centor criteria add age to the original Centor criteria. ${ }^{13,14}$ The FeverPAIN score criteria are Fever (during the previous 24 hours), Purulence (pus on tonsils), Attend rapidly (within 3 days after onset of symptoms), severely Inflamed tonsils, and No cough or coryza; each of the criteria is worth 1 point (maximum score of 5). A score of 0 or 1 is associated with a $13 \%$ to $18 \%$ likelihood of isolating Streptococcus. A score of 2 or 3 is associated with a $34 \%$ to $40 \%$ likelihood of isolating Streptococcus. A score of 4 or 5 is associated with a $62 \%$ to $65 \%$ likelihood of isolating Streptococcus. In contrast, the modified Centor criteria are age 3 to 14 years, history of fever (over $38^{\circ} \mathrm{C}$ ), absence of cough, exudate or swelling on tonsils, and tender/swollen anterior cervical lymph nodes; each of the criteria is worth 1 point (maximum score of 5); note that 0 points are assigned for age 15 to 44 years, whereas -1 point is given for age $\geq 45$ years. A score of $-1,0$ or 1 is associated with a $1 \%$ to $10 \%$ likelihood of isolating Streptococcus. A score of 2 or 3 is associated with an $11 \%$ to $35 \%$ likelihood of isolating Streptococcus. A score of 4 or 5 is associated with a $51 \%$ to $53 \%$

\section{急性咽喉炎在基層醫療的抗生素治療} 基層醫療抗生素導向計劃諮詢小組

衞生署衞生防護中心已召開基層醫療抗生素導向計劃諮詢小組，以製 訂優化合理使用抗生素及提升基層醫療抗生素導向計劃執行的指引和 策略。急性咽喉炎是香港基層醫療門診患者中最常見的病症之一。諮 詢小組根據現有最佳的臨床證據、本地病原體流行情況和相關的藥敏 測試結果以及本地常見做法, 對急性鏈球菌性咽喉炎的診斷和抗生素 治療提出實用建議

likelihood of isolating Streptococcus. There is currently uncertainty about which clinical scoring tool is more effective.

Based on the clinical experience that RADT is not commonly available, and throat culture is time consuming, requiring a 2- to 3-day turnaround time, the Advisory Group agreed that using clinical scoring criteria is preferential to not using any laboratory tests or clinical scoring criteria, and the modified Centor criteria are more widely and easily used (Table 1).

\section{Antibiotic treatment of acute streptococcal pharyngitis}

Although the symptoms of acute streptococcal pharyngitis resolve without antibiotic treatment, there are arguments that justify antibiotic treatment for acute symptom relief, prevention of suppurative and non-suppurative complications, and reduction of communicability. A recent systematic review on antibiotics for sore throat found that the clinical benefits were modest and required treatment of many with antibiotics for one to benefit (the number of people with sore throat who must be treated to resolve the symptoms of one by day 3 was about 3.7 for those with positive throat swabs for Streptococcus; 6.5 for those with a negative swab, and 14.4 for those in whom no swab had been taken). ${ }^{15}$ Antibiotic treatment may shorten the duration of sore throat by 1 to 2 days. Antibiotics may prevent complications of GAS infection, including acute rheumatic fever or suppurative complications. ${ }^{15}$ Out-patients are considered no longer contagious after 24 hours of antibiotic treatment. However, little evidence supports the prevention of poststreptococcal glomerulonephritis by antibiotic treatment. ${ }^{15}$

Although scarlet fever occurs throughout the year, there has been a seasonal pattern in Hong Kong, with higher activity observed from May to June and from November to March in the past few years. ${ }^{16}$ Scarlet fever is a bacterial infection caused by GAS, and it classically presents with fever, sore throat, red and swollen tongue (known as strawberry tongue), 
TABLE I. Modified Centor score

\begin{tabular}{|c|c|c|c|c|c|}
\hline Criteria & & & & & Score \\
\hline \multicolumn{6}{|c|}{ Age range (Group A Streptococcus pharyngitis is rare under 3), years } \\
\hline $3-14$ & & & & & +1 \\
\hline $15-44$ & & & & & 0 \\
\hline$\geq 45$ & & & & & -1 \\
\hline \multicolumn{6}{|l|}{ Fever (temperature $>38^{\circ} \mathrm{C} / 100.4^{\circ} \mathrm{F}$ ) } \\
\hline No & & & & & 0 \\
\hline Yes & & & & & +1 \\
\hline \multicolumn{6}{|l|}{ Cough } \\
\hline Present & & & & & 0 \\
\hline Absent & & & & & +1 \\
\hline \multicolumn{6}{|l|}{ Exudate or swelling on tonsils } \\
\hline No & & & & & 0 \\
\hline Yes & & & & & +1 \\
\hline \multicolumn{6}{|l|}{ Tender/swollen anterior cervical lymph nodes } \\
\hline No & & & & & 0 \\
\hline Yes & & & & & +1 \\
\hline Total score & -1 or 0 & 1 & 2 & 3 & 4 or 5 \\
\hline Likelihood of acute streptococcal pharyngitis (\%) & $1-2.5$ & $5-10$ & $11-17$ & $28-35$ & $51-53$ \\
\hline
\end{tabular}

and erythematous rash with a sandpaper texture. It is mainly a clinical diagnosis and can be treated by appropriate antibiotics effectively.

After considering the benefits and risks (eg, allergies and side-effects) of antibiotic treatment, the Advisory Group agreed that antibiotic treatment is indicated for out-patients presenting with a sore throat and a modified Centor score of 4 or 5 and for out-patients with positive laboratory results or certain special reasons (eg, clinical scarlet fever, household contact with scarlet fever, or known rheumatic heart disease) [Table 2].

Oral penicillin $\mathrm{V}$ or amoxicillin are the recommended antibiotics of choice for out-patients who are not allergic to these agents. Resistance of GAS to penicillins and other beta-lactams has not been reported. ${ }^{17}$ First-generation cephalosporins (eg, oral cephalexin) are the first-line agents for out-patients with penicillin allergies who are not anaphylactically allergic. Other cephalosporins (eg, oral cefaclor, cefuroxime) are alternatives, but they are not favoured as the first-line agents because of their broad spectrum of activity. Resistance of GAS to macrolides (eg, oral azithromycin, clarithromycin, erythromycin) is known to be common in Hong Kong. Erythromycin-resistant isolates of GAS are regarded as resistant to clarithromycin and azithromycin as well. ${ }^{17}$ According to data from the Microbiology Division of the Public Health Laboratory Services Branch of the Centre for Health
Protection, which undertakes bacterial isolation and antibiotic susceptibility testing in public and private out-patient settings in Hong Kong, the erythromycin resistance rates of beta-haemolytic streptococci (in which GAS contributed to majority of them) in throat swab specimens has risen to $59.1 \%$ in the last few years. ${ }^{18}$ Studies have shown that the erythromycin resistance rates of GAS isolates were $4 \%$ in the United States, 3.2\% in France, 32.8\% in Spain, and 65\% in Taiwan. ${ }^{19-22}$ Respiratory fluoroquinolones (eg, oral levofloxacin) are active against GAS, but they have an unnecessarily broad spectrum of activity and are not recommended for routine treatment of acute streptococcal pharyngitis. ${ }^{6}$ Excessive use of respiratory fluoroquinolones may lead to delay in the diagnosis of tuberculosis and increased fluoroquinolone resistance among Mycobacterium tuberculosis in Hong Kong. ${ }^{23}$ Trimethoprimsulfamethoxazole should not be used because it does not eradicate GAS from out-patients with acute pharyngitis. $^{6}$

After considering the basic principle that narrow-spectrum antibiotics should be used as the first-line agents to treat an infection that is not lifethreatening, the Advisory Group agreed that oral penicillin $\mathrm{V}$, amoxicillin or cephalexin are the firstline agents to treat acute streptococcal pharyngitis (Table 2). Treatment with oral macrolides or respiratory fluoroquinolones requires sound justifications, including documented history of beta- 
TABLE 2. Recommended antibiotic treatment of acute streptococcal pharyngitis*

\begin{tabular}{|c|c|c|c|c|}
\hline Drug (route) & $\begin{array}{l}\text { Dosage and frequency, } \\
\text { adult (usual) }\end{array}$ & $\begin{array}{l}\text { Dosage and frequency, children } \\
\text { (usual) }\end{array}$ & $\begin{array}{l}\text { Duration } \\
\text { (usual) }\end{array}$ & Remarks \\
\hline \multicolumn{5}{|l|}{ First line } \\
\hline Penicillin V (oral) & $500 \mathrm{mg} 2$ to 4 times daily & $\begin{array}{l}\text { If } \leq 27 \mathrm{~kg}: 250 \mathrm{mg} 2 \text { to } 3 \text { times daily } \\
\text { If }>27 \mathrm{~kg}: 500 \mathrm{mg} 2 \text { to } 4 \text { times daily }\end{array}$ & 5-7 days $\dagger$ & \\
\hline Amoxicillin (oral) & $\begin{array}{l}1000 \mathrm{mg} \text { once daily or } \\
500 \mathrm{mg} 2 \text { to } 3 \text { times daily }\end{array}$ & $\begin{array}{l}50 \mathrm{mg} / \mathrm{kg} \text { (maximum }=1000 \mathrm{mg} \text { ) once } \\
\text { daily or } 25 \mathrm{mg} / \mathrm{kg} \text { (maximum }=500 \mathrm{mg} \text { ) } \\
2 \text { to } 3 \text { times daily }\end{array}$ & 5-7 days $\dagger$ & \\
\hline Cephalexin (oral) & $500 \mathrm{mg} 2$ to 4 times daily & $\begin{array}{l}20 \mathrm{mg} / \mathrm{kg} \text { (maximum }=500 \mathrm{mg}) 2 \text { to } 4 \\
\text { times daily }\end{array}$ & 5-7 days $\dagger$ & $\begin{array}{l}\text { - Cephalosporins should be avoided } \\
\text { in individuals with immediate } \\
\text { (anaphylactic) type hypersensitivity to } \\
\text { penicillin }\end{array}$ \\
\hline \multicolumn{5}{|l|}{ Second line } \\
\hline $\begin{array}{l}\text { Clarithromycin } \\
\text { (oral) }\end{array}$ & 250 mg twice daily & $\begin{array}{l}7.5 \mathrm{mg} / \mathrm{kg} \text { (maximum = } 250 \mathrm{mg} \text { ) twice } \\
\text { daily }\end{array}$ & 5 days $†$ & $\begin{array}{l}\text { - For individuals with penicillin allergy } \\
\text { - Erythromycin-resistant isolates are } \\
\text { regarded as resistant to clarithromycin } \\
\text { and azithromycin as well }\end{array}$ \\
\hline $\begin{array}{l}\text { Azithromycin } \\
\text { (oral) }\end{array}$ & 500 mg once daily & $\begin{array}{l}12 \mathrm{mg} / \mathrm{kg} \text { (maximum = } 500 \mathrm{mg} \text { ) once } \\
\text { daily }\end{array}$ & 3 days & $\begin{array}{l}\text { - For individuals with penicillin allergy } \\
\text { - Erythromycin-resistant isolates are } \\
\text { regarded as resistant to clarithromycin } \\
\text { and azithromycin as well }\end{array}$ \\
\hline
\end{tabular}

* Primary care doctors should tailor antibiotic treatment to their clinical judgement. Definitive therapy should be based on microbiological and antibiotic susceptibility results, if available

† For out-patients presenting with a sore throat and a modified Centor score of 4 or 5, a short course of oral antibiotic treatment is recommended. However, for out-patients with positive laboratory results for group A Streptococcus or certain special reasons (eg, clinical scarlet fever, household contact with scarlet fever, or known rheumatic heart disease), a 10 -day course of oral penicillin V, amoxicillin, cephalexin or clarithromycin, or a 5-day course of oral azithromycin is recommended to achieve maximal eradication of group A Streptococcus from the pharynx for primary prevention of acute rheumatic fever

lactam allergy or intolerance, positive throat culture results, and associated antibiotic susceptibility profiles.

A 10-day course of oral penicillin $\mathrm{V}$, amoxicillin, cephalexin or clarithromycin, or a 5-day course of oral azithromycin is recommended by the Infectious Diseases Society of America, the American College of Physicians, and the American Academy of Pediatrics to achieve maximal eradication of GAS from the pharynx for primary prevention of acute rheumatic fever. ${ }^{6-8}$ However, a recent systematic review comparing a 3- to 6-day course of oral antibiotics (primarily cephalosporins) with a conventional 10-day course of oral penicillin found similar effectiveness in children, but no conclusions could be drawn on the complication rates of acute rheumatic fever and poststreptococcal glomerulonephritis. ${ }^{24}$ Furthermore, a 5-day course of antibiotic treatment is sufficient to mitigate the clinical course of group C Streptococcus and group G Streptococcus pharyngitis, as acute rheumatic fever is not a complication of infections due to these organisms. ${ }^{8}$

Based on the clinical experience that the prevalence of acute rheumatic fever is very low in Hong Kong nowadays, the Advisory Group agreed that a 5- to 7-day course of oral penicillin V, amoxicillin or cephalexin, or a 5-day course of oral clarithromycin, or a 3-day course of oral azithromycin is sufficient to treat out-patients presenting with a sore throat and a modified Centor score of 4 or 5 . However, for out-patients with positive laboratory results for GAS or certain special reasons (eg, clinical scarlet fever, household contact with scarlet fever, or known rheumatic heart disease), a 10-day course of oral penicillin V, amoxicillin, cephalexin or clarithromycin, or a 5-day course of oral azithromycin is recommended to achieve maximal eradication of GAS from the pharynx for primary prevention of acute rheumatic fever (Table 2).

\section{Other issues}

Alternative diagnosis should be considered for outpatients who present with unusually severe signs and symptoms, such as difficulty swallowing, drooling, neck tenderness or swelling, or systemic unwellness. They should be evaluated for potentially dangerous infections (eg, peritonsillar abscess, retro-/parapharyngeal abscess, acute epiglottitis and systemic infections). Out-patients who do not improve within 5 to 7 days or who have worsening symptoms should be evaluated for a previously unsuspected diagnosis (eg, infectious mononucleosis, primary 
HIV infection, or gonococcal pharyngitis). Infectious mononucleosis is a clinical syndrome characterised by fever, severe pharyngitis (which lasts longer than GAS pharyngitis), cervical or diffuse lymphadenopathy, and prominent constitutional symptoms. Out-patients who have infectious mononucleosis and are treated with amoxicillin may develop a generalised, erythematous, maculopapular rash, and this should not be regarded as a penicillin allergy. A properly taken sexual history may hint at possibility of sexually transmitted infections like HIV and gonorrhoea.

Management of out-patients with infections should be individualised. Primary care doctors should check, document, and inform out-patients well about antibiotic treatment (eg, indications, side-effects, allergies, contra-indications, potential drug-drug interactions). Out-patients should take antibiotics exactly as prescribed by their doctors. If their symptoms change, persist, or get worse, they should seek medical advice promptly.

Primary care doctors are invited to show their commitment on judicious use of antibiotics by visiting the "I Pledge" website (https://www. chp.gov.hk/en/static/100755.html) and signing a certificate on pledging to use antibiotics responsibly. Furthermore, this invitation is open to general public. Primary care doctors can engage their out-patients on "I Pledge" during clinical encounters to facilitate shared decision making on antibiotic prescribing.

\section{Conclusion}

Acute pharyngitis is one of the most common conditions among out-patients in primary care in Hong Kong. Practical recommendations on the diagnosis and antibiotic treatment of acute streptococcal pharyngitis are made in consultation with key stakeholders in primary care settings such that the recommendations can be tailored to their needs. The recommendations are under regular review, in consideration of the latest research, together with local prevalence of pathogens and associated antibiotics susceptibility profiles, and common local practice.

\footnotetext{
The Advisory Group on Antibiotic Stewardship Programme in Primary Care (2017-2018)

${ }^{1}$ Angus MW Chan, MB, ChB (Glasg), FHKAM (Family Medicine)

${ }^{2}$ Winnie WY Au, MB, BS

${ }^{3}$ David VK Chao, FRCGP, FHKAM (Family Medicine)

${ }^{4}$ K Choi, MB, BS, FHKAM (Family Medicine)

${ }^{5}$ KW Choi, MB, ChB, FHKAM (Medicine)

${ }^{6}$ Sarah MY Choi, MB, ChB, FHKAM (Community Medicine)

${ }^{7}$ Y Chow, MB, BS, FHKAM (Psychiatry)

${ }^{8}$ Cecilia YM Fan, MB, BS, FHKAM (Family Medicine)

${ }^{9} \mathrm{PL} \mathrm{Ho}, \mathrm{MD}, \mathrm{FACP}$
}

${ }^{10}$ Eric MT Hui, FHKCFP, FHKAM (Family Medicine)

${ }^{11} \mathrm{KH}$ Kwong, MB, BS, MFM (Clin) (Monash)

12 Benjamin YS Kwong, BSc Pharm, MPharmS

${ }^{13}$ TP Lam, MD, FHKAM (Family Medicine)

${ }^{14}$ Edman TK Lam, MB, ChB, FHKAM (Pathology)

${ }^{14}$ KW Lau, BSc Pharm, MPharmS

${ }^{14}$ Leo Lui, MB, BS, FHKAM (Pathology)

${ }^{14}$ Ken HL Ng, MB, BS, FHKAM (Pathology)

${ }^{15}$ Martin CS Wong, MD, FHKAM (Family Medicine)

${ }^{14}$ TY Wong, MB, BS, FHKAM (Medicine)

${ }^{16}$ CF Yeung, MB, BS, FHKAM (Paediatrics)

${ }^{17}$ Joyce HS You, PharmD, BCPS (AQ Infectious Diseases)

${ }^{18}$ Raymond WH Yung, MB, BS, FHKAM (Pathology)

${ }^{1}$ Hong Kong College of Family Physicians, Hong Kong

${ }^{2}$ Infection Control Branch, Centre for Health Protection,

Department of Health, Hong Kong

${ }^{3}$ Department of Family Medicine and Primary Health Care, United Christian Hospital, Hospital Authority, Hong Kong

${ }^{4}$ Hong Kong Medical Association, Hong Kong

${ }^{5}$ Hong Kong Society for Infectious Diseases, Hong Kong

${ }^{6}$ Primary Care Office, Department of Health, Hong Kong

Quality HealthCare Medical Services Limited, Hong Kong

${ }^{8}$ Professional Development and Quality Assurance, Department of Health, Hong Kong

${ }^{9}$ IMPACT Editorial Board, Reducing bacterial resistance with IMPACT, 5th edition, Hong Kong

${ }^{10}$ Department of Family Medicine, New Territories East Cluster, Hospital Authority, Hong Kong

${ }^{11}$ Human Health Holdings Limited, Hong Kong

${ }^{12}$ Chief Pharmacist's Office, Hospital Authority, Hong Kong

${ }^{13}$ Department of Family Medicine and Primary Care, The University of Hong Kong, Hong Kong

${ }^{14}$ Infection Control Branch, Centre for Health Protection, Department of Health, Hong Kong

${ }^{15}$ Hong Kong Academy of Medicine, Hong Kong

${ }^{16}$ Hong Kong Doctors Union, Hong Kong

${ }^{17}$ School of Pharmacy, The Chinese University of Hong Kong, Hong Kong

${ }^{18}$ Hong Kong Sanatorium \& Hospital, Hong Kong

\section{Author contributions}

All authors have made substantial contributions to the viewpoints of this study, literature review, and critical revision for important intellectual content. ETK Lam was responsible for literature search and drafting of the manuscript. All authors had full access to the data, contributed to the study, approved the final version for publication, and take responsibility for its accuracy and integrity.

\section{Conflicts of interest}

As editors of this journal, DVK Chao and MCS Wong were not involved in the peer review process of this article. All other authors have no conflicts of interest to disclose.

\section{Declaration}

An earlier version of this article was published online in the Centre for Health Protection website, November 2017 (https://www.chp.gov.hk/files/pdf/guidance_notes_acute_ pharynitis_full.pdf). 


\section{Funding/support}

This research received no specific grant from any funding agency in the public, commercial, or not-for-profit sectors.

\section{References}

1. Lam TP, Ho PL, Lam KF, Choi K, Yung R. Use of antibiotics by primary care doctors in Hong Kong. Asia Pac Fam Med 2009;8:5.

2. Kung K, Wong CK, Wong SY, et al. Patient presentation and physician management of upper respiratory tract infections: a retrospective review of over 5 million primary clinic consultations in Hong Kong. BMC Fam Pract 2014;15:95.

3. Alcaide ML, Bisno AL. Pharyngitis and epiglottitis. Infect Dis Clin North Am 2007;21:449-69.

4. Wong $\mathrm{MC}$, Chung $\mathrm{CH}$. Group A streptococcal infection in patients presenting with a sore throat at an accident and emergency department: prospective observational study. Hong Kong Med J 2002;8:92-8.

5. Chan JY, Yau F, Cheng F, Chan D, Chan B, Kwan M. Practice recommendation for the management of acute pharyngitis. Hong Kong J Paediatr 2015;20:156-62.

6. Shulman ST, Bisno AL, Clegg HW, et al. Clinical practice guideline for the diagnosis and management of group A streptococcal pharyngitis: 2012 update by the Infectious Diseases Society of America. Clin Infect Dis 2012;55:e86102.

7. Harris AM, Hicks LA, Qaseem A; High Value Care Task Force of the American College of Physicians and for the Centers for Disease Control and Prevention. Appropriate antibiotic use for acute respiratory tract infection in adults: advice for high-value care from the American College of Physicians and the Centers for Disease Control and Prevention. Ann Intern Med 2016;164:425-34.

8. Gerber MA, Baltimore RS, Eaton CB, et al. Prevention of rheumatic fever and diagnosis and treatment of acute streptococcal pharyngitis: a scientific statement from the American Heart Association Rheumatic Fever, Endocarditis, and Kawasaki Disease Committee of the Council on Cardiovascular Disease in the Young, the Interdisciplinary Council on Functional Genomics and Translational Biology, and the Interdisciplinary Council on Quality of Care and Outcomes Research: endorsed by the American Academy of Pediatrics. Circulation 2009;119:1541-51.

9. ESCMID Sore Throat Guideline Group, Pelucchi C, Grigoryan L, et al. Guideline for the management of acute sore throat. Clin Microbiol Infect 2012;18(Suppl 1):1-28.

10. Public Health England, UK Government. Management and treatment of common infections. Antibiotic guidance for primary care: For consultation and local adaptation. 2017. Available from: https://www.gov.uk/government/ publications/managing-common-infections-guidance-forprimary-care. Accessed 6 Oct 2017.

11. The National Institute for Health and Care Excellence, Public Health England, UK Government. Sore throat (acute): antimicrobial prescribing. 2018. Available from: https://www.nice.org.uk/guidance/ng84. Accessed $13 \mathrm{Jul}$
2018.

12. Little P, Moore M, Hobbs FD, et al. PRImary care Streptococcal Management (PRISM) study: identifying clinical variables associated with Lancefield group A $\beta$-haemolytic Streptococci and Lancefield non-Group A streptococcal throat infections from two cohorts of patients presenting with an acute sore throat. BMJ Open 2013;3:e003943.

13. Centor RM, Witherspoon JM, Dalton HP, Brody CE, Link $\mathrm{K}$. The diagnosis of strep throat in adults in the emergency room. Med Decis Making 1981;1:239-46.

14. McIsaac WJ, White D, Tannenbaum D, Low DE. A clinical score to reduce unnecessary antibiotic use in patients with sore throat. CMAJ 1998;158:75-83.

15. Spinks A, Glasziou PP, Del Mar CB. Antibiotics for sore throat. Cochrane Database Syst Rev 2013;(11):CD000023.

16. Centre for Health Protection, Department of Health, Hong Kong SAR Government. Letter to doctors: further increase in scarlet fever activity in Hong Kong. 2017. Available from: https://www.chp.gov.hk/files/pdf/letters_ to_doctors_20171204.pdf. Accessed 13 Jul 2018.

17. Clinical and Laboratory Standards Institute. Performance standards for antimicrobial susceptibility testing. 27th ed. 2017. Available from: https://clsi.org/media/1469/ m100s27_sample.pdf. Accessed 6 Oct 2017.

18. Centre for Health Protection, Department of Health, Hong Kong SAR Government. Bacterial pathogen isolation and percentage of antimicrobial resistance-out-patient setting. 2014-2018. Available from http://www.chp.gov.hk/ en/data/1/10/641/697/3345.html. Accessed 13 Jul 2018.

19. Tanz RR, Shulman ST, Shortridge VD, et al. Communitybased surveillance in the United States of macrolideresistant pediatric pharyngeal group A Streptococci during 3 respiratory disease seasons. Clin Infect Dis 2004;39:1794801.

20. d'Humières C, Cohen R, Levy C, et al. Decline in macrolideresistant Streptococcus pyogenes isolates from French children. Int J Med Microbiol 2012;302:300-3.

21. Rubio-López V, Valdezate S, Alvarez D, et al. Molecular epidemiology, antimicrobial susceptibilities and resistance mechanisms of Streptococcus pyogenes isolates resistant to erythromycin and tetracycline in Spain (1994-2006). BMC Microbiol 2012;12:215.

22. Chuang PK, Wang SM, Lin HC, et al. The trend of macrolide resistance and emm types of group A Streptococci from children at a medical center in southern Taiwan. J Microbiol Immunol Infect 2015;48:160-7.

23. Ho PL, Wu TC, Chao DV, et al, editors. Reducing bacterial resistance with IMPACT-Interhospital Multi-disciplinary Programme on Antimicrobial ChemoTherapy. 5th version. 2017. Available from: https://www.chp.gov.hk/files/pdf/ reducing_bacterial_resistance_with_impact.pdf. Accessed 6 Oct 2017.

24. Altamimi S, Khalil A, Khalaiwi KA, Milner RA, Pusic MV, Al Othman MA. Short-term late-generation antibiotics versus longer term penicillin for acute streptococcal pharyngitis in children. Cochrane Database Syst Rev 2012;(8):CD004872. 